\title{
ANÁLISE COMPARATIVA ENTRE A COMPOSIÇÃO MINISTERIAL DO GOVERNO WASHINGTON LUÍS E A PRIMEIRA EQUIPE DE MINISTROS DO GOVERNO PROVISÓRIO DE GETÚLIO VARGAS
}

\author{
Natália Cristina Granato ${ }^{1}$
}

\begin{abstract}
Resumo
O presente artigo pretende analisar a composição ministerial do governo Washington Luís, presidente derrubado pela Revolução de 1930. A partir destes dados, uma análise comparativa será feita em relação à primeira composição ministerial do governo provisório de Getúlio Vargas. Objetiva-se destacar as principais características da composição ministerial em um momento de mudanças na política brasileira. A pesquisa se realizou a partir da coleta de dados biográficos dos oito ministros do governo de Washington Luís e dos nove ministros que fizeram parte da primeira equipe do governo provisório de Getúlio Vargas. A hipótese inicial feita a partir da comparação é a de que o governo de Washington Luís possuía estabilidade política em relação ao governo Vargas, marcado pela instabilidade característica dos primeiros momentos do governo provisório. A pesquisa utilizou-se o método prosopográfico para a análise das equipes ministeriais, coletando dados a partir dos verbetes sobre os ministros no Dicionário Histórico-Biográfico Brasileiro. A partir deles, assinalam-se algumas variáveis significativas, tais como as propostas por Stone (2011), afirmando as características comuns identificadas no estudo de suas biografias. Entre os principais resultados da análise comparativa, destaca-se que o ministério de Washington Luís demonstrou agregação de forças políticas de diversas regiões do país. Trata-se de uma equipe estável politicamente. Por sua vez, a análise da primeira equipe de ministros nomeada pelo Governo Provisório demonstra uma composição que procurou agregar os estados cujas oligarquias dissidentes apoiaram a Revolução. No entanto, essa agregação de forças não demonstrou estabilidade política e gerou inúmeros descontentamentos e desgastes nos primeiros meses do governo provisório. Na análise do ministério Vargas, destaca-se a força política do Rio Grande do Sul e Minas Gerais. Outros pontos destacados referem-se ao caráter conservador de algumas nomeações empreendidas pelo presidente, bem como ao prestígio de lideranças associadas à sua pessoa.
\end{abstract}

Palavras-Chave: Prosopografia; Composição ministerial; Washington Luís; Getúlio Vargas.

\section{INTRODUÇÃO}

O presente artigo pretende analisar a composição ministerial do governo Washington Luís, que será comparada com a composição ministerial do governo Vargas. A comparação entre os dois

\footnotetext{
${ }^{1}$ Doutoranda em Sociologia pela Universidade Federal do Paraná. E-mail: nataliagranato@ hotmail.com. ID ORCID: https://orcid.org/0000-0002-6090-0428.
} 
governos deve-se ao fato de que esse período foi atravessado pela Revolução de 1930. Tradicionalmente considerada um "marco na história contemporânea do país" pela sociologia política e pela historiografia, ela tem um importante significado político (MARTINS, 1983).

A Revolução de 1930 questionou a autonomia política e administrativa dos estados e fomentou a centralização estatal e as novas práticas políticas-eleitorais. Seus primeiros meses registraram uma "política revolucionária", questionando as práticas oligárquicas características da "velha política" exercida pelos coronéis e clãs familiares, que se perpetuavam no poder.

No entanto, a despeito do discurso "regenerador" do movimento político, boa parte da literatura sobre a Revolução de 1930 caracteriza este processo como "modernização conservadora". O conceito de Barrington Moore Junior é aplicado ao caso brasileiro para a explicitação de que não houve uma "Revolução" no estilo clássico do termo (tendo como referência a revolução francesa, na qual a burguesia, como classe economicamente dominante em ascensão assume a hegemonia política, promovendo rupturas com a Nobreza e o Antigo Regime, tornando-se uma classe politicamente dominante) e sim uma ruptura de estilo conservador. A burguesia brasileira e os interesses urbanos e industriais não conseguem impor totalmente frente às antigas classes dominantes, como é o caso das oligarquias rurais, cabendo ao Estado o papel de incorporação da nascente burguesia (industrial e comercial), conservando as velhas estruturas de propriedade e não deixando de atender os interesses dos setores oligárquicos que detinham o poder (PIRES; RAMOS, 2009).

A Revolução de 1930 buscou a incorporação das aspirações das classes em ascensão (burguesia industrial, operariado urbano) nas pautas do Estado (ou seja, quebrou o monopólio exclusivo das oligarquias rurais sobre o Estado). Mas isso não significa que tais classes hegemônicas da República Velha foram excluídas do processo político que estavam em reformulação. Luciano Martins (1983, p.673) caracteriza a Revolução de 1930 como uma "crise da oligarquia", pois se a estrutura agrária não foi modificada, logo as bases sociais do coronelismo foram mantidas, bem como a hegemonia do voto rural. Tal processo resultou na modernização da manipulação eleitoral e do patrimonialismo e também proporcionou a inclusão de atores emergentes na cena política, algo que “o sistema representativo da confederação oligárquica fora incapaz de resolver” (MARTINS, 1983).

Outra autora que compartilha deste ponto de vista é Maria do Carmo Campello de Souza, salientando que os interesses econômicos dominantes do período anterior não foram marginalizados. Segundo a autora, a Revolução de 1930 redefiniu os "canais de acesso e influência para a articulação de todos os interesses, velhos ou novos, com o poder central" (SOUZA, 1976, p.85). 
$\mathrm{Na}$ análise da composição ministerial na transição de um governo para o outro, com mandatos inseridos na Revolução de 1930, objetiva-se comparar quais foram os perfis dos agentes políticos para a nomeação aos ministérios, identificando quais são as semelhanças e as diferenças entre os governos, bem como as mudanças e permanências registradas nos padrões de nomeação.

A pesquisa se realizou a partir da coleta de dados biográficos dos oito ministros do governo de Washington Luís e dos nove ministros que fizeram parte da primeira equipe do governo provisório de Getúlio Vargas. A hipótese inicial feita a partir da comparação é a de que o governo de Washington Luís possuía estabilidade política em relação ao governo Vargas, marcado pela instabilidade característica dos primeiros momentos do governo provisório.

Para a análise das equipes ministeriais, utilizamos o método prosopográfico, coletando dados a partir dos verbetes sobre os ministros no Dicionário Histórico-Biográfico Brasileiro. A partir deles, assinalam-se algumas variáveis significativas, afirmando as características comuns identificadas no estudo de suas biografias. Prosopografia ou biografia coletiva, segundo Lawrence Stone (2011), é uma técnica que investiga características comuns de um grupo de atores através de um estudo coletivo de suas trajetórias de vida. Coletaremos variáveis biográficas como nome, filiação, local de nascimento, cargos políticos ocupados, profissão e partido político de origem dos agentes que foram nomeados para os ministérios.

O trabalho está dividido em duas partes. A primeira tratará da análise do ministério de Washington Luís, com o objetivo de identificar as suas principais características. A segunda parte visa analisar a primeira composição ministerial do Governo Provisório, através do método prosopográfico. Investigaremos apenas a primeira composição, visto que, diferente do governo Washington Luís, o governo Vargas demonstrou grande rotatividade de poder, o que foi visível nas recorrentes trocas de nomes nas pastas ministeriais.

\section{ANÁLISE DO MINISTÉRIO DE WASHINGTON LUÍS}

O governo Washington Luís foi o último a pertencer ao rol de presidentes da chamada "República Velha" ou Primeira República. A Primeira República era caracterizada pela preponderância dos mesmos grupos, famílias e frações de classe exercendo a dominação política nos estados como símbolo de prestígio e distinção em relação aos outros grupos sociais, excluídos do sistema oligárquico. Esta dominação, porém, não se dava sem conflitos no interior destes grupos dominantes, as oligarquias regionais disputavam entre si recursos políticos e econômicos, 
barganhavam favores ante à máquina administrativa, dividiam-se entre partidos políticos, entre outras disputas.

As primeiras contestações a este sistema oligárquico começaram a ganhar fôlego a partir das eleições presidenciais 1922, disputada entre o candidato oficial da oligarquia mineira, Arthur Bernardes e o candidato da oposição, componente da oligarquia fluminense, Nilo Peçanha. O primeiro, como o esperado, venceu a disputa, mas nesta ocorreu o fato conhecido posteriormente de "Episódio das Cartas Falsas", que culminou no início do protesto tenentista. A década de 1920 foi caracterizada pelos primeiros passos da urbanização e industrialização, trazendo consigo as inquietações se segmentos sociais como os operários, os comerciários, os profissionais liberais, entre outros. No processo de inclusão destes novos atores políticos, revela-se a incapacidade do sistema oligárquico na aglutinação de diferentes interesses (MARTINS, 1983), o que culminou na sua crise.

A tabela a seguir apresenta informações sobre a composição ministerial do governo de Washington Luís.

TABELA 1 - MINISTROS DE WASHINGTON LUÍS: PASTA, PERÍODO, UF E ANO DE NASCIMENTO

\begin{tabular}{|l|l|l|l|}
\hline Ministro & Pasta & Período & UF \\
\hline Arnaldo de Siqueira Pinto da Luz (1875-1961) & Marinha & $1926-1930$ & RJ \\
\hline Augusto Viana do Castelo (1874-1953) & Justiça & $1926-1930$ & MG \\
\hline Geminiano Lira Castro (1863-1936) & Agricultura & $1926-1930$ & PA \\
\hline Getúlio Vargas (1882-1954) & Fazenda & $1926-1927$ & RS \\
\hline Francisco C.de Oliveira Botelho (1868-1943) & Fazenda & $1927-1930$ & RJ \\
\hline Nestor Sezefredo dos Passos (1872-1941) & Guerra & $1926-1930$ & SC \\
\hline Otávio Mangabeira (1886-1970) & Relações Exteriores & $1926-1930$ & BA \\
\hline Vítor Konder (1886-1941) & $\begin{array}{l}\text { Viação e Obras } \\
\text { Públicas }\end{array}$ & $1926-1930$ & SC \\
\hline
\end{tabular}

FONTE: DHBB/CPDOC/FGV. ORGANIZAÇÃO: A autora (2020)

A partir desses dados, percebemos a alta estabilidade registrada pelo governo, considerando o tempo de permanência dos ministros nos seus respectivos cargos. Com exceção a Getúlio Vargas, todos os ministros escolhidos no início do mandato conservaram-se na pasta até o final do mandato presidencial.

A única troca registrada está relacionada a formação de uma dissidência no âmbito nacional. Getúlio Vargas possuía grande apreço à liderança de Washington Luís, e ocupava a pasta da Fazenda, uma das mais importantes funções para o governo. Embora registrando respeito ao presidente, Vargas pediu demissão do cargo para concorrer ao governo do estado do Rio Grande do Sul, saindo-se vitorioso. Os descontentamentos dos estados quanto aos rumos tomados pela política econômica vinham registrando grandes proporções, o que fortaleceu a oposição. Com a quebra da bolsa de 
valores de Nova Iorque, em 1929, a crise econômica mundial provocou efeitos nocivos ao capitalismo brasileiro.

Quanto aos aspectos biográficos dos ministros, identificamos a diversidade de estados contemplados por uma vaga ministerial. Dos 8 ministros do governo Washington Luís, 2 nasceram no Rio de Janeiro e 2 nasceram em Santa Catarina. Os outros 4 ministros eram naturais de Minas Gerais, Pará, Rio Grande do Sul e Bahia. É importante assinalar que, em parte das narrativas sobre o governo Washington Luís, em especial aquelas vinculadas aos discursos históricos dos "vencedores" do movimento de 1930, há o destaque à ideia de que o estado de São Paulo, ao qual pertencia o presidente, era o mais considerado em termos políticos. Ao considerarmos a política econômica, podemos considerar parte dessa narrativa como verdadeira. Mesmo assim, elas devem ser vistas com ressalvas, pois a política de proteção à lavoura cafeeira praticada pelo governo gerava descontentamentos entre os próprios produtores paulistas. Em termos políticos, o grupo Washington Luís, reunido no Partido Republicano Paulista, possuía o direcionamento da conservação de paulistas no poder executivo nacional, o que pode ser visível na escolha do seu sucessor, Júlio Prestes, à revelia de importantes oligarquias, como a de Minas Gerais e a do Rio Grande do Sul. No entanto, também percebemos que o governo de Washington Luís possuía como prática a agregação de diferentes oligarquias em seu interior, agregando ministros do Norte ao Sul do país. Na composição ministerial, por exemplo, não havia nenhum paulista como representante, e isso corrobora com a tentativa de divisão de poder e influência entre o presidente paulista e as oligarquias estaduais.

No que se refere às origens sociais e políticas dos ministros do governo Washington Luís, percebemos a forte vinculação deles com as elites oligárquicas dos seus respectivos estados. O ministro da Marinha, Arnaldo de Siqueira Pinto da Luz, era filho de José Pinto da Luz, que também ocupou o cargo de ministro da Marinha entre os anos de 1899 e 1902, no governo Campos Sales (1898-1902). Arnaldo de Siqueira era ministro da Marinha no governo Arthur Bernardes, antecessor de Washington Luís (DHBB-CPDOC FGV²). Isso indica o alto grau de coesão entre as elites e baixo grau de renovação entre os governos da Primeira República.

O ministro da Justiça, Augusto Viana do Castelo, era filho de Felicíssimo de Sousa Viana, major do Exército brasileiro, importante quadro militar em Minas Gerais. Após Augusto Castelo formar-se em Direito, exerceu o cargo de procurador. Em 1906, elegeu-se 1906 foi eleito deputado federal por Minas Gerais, permanecendo no cargo até 1914. Retornou ao posto em 1921, licenciando-

\footnotetext{
${ }^{2}$ DHBB-CPDOC FGV. Verbete Arnaldo Siqueira Pinto da Luz. Assinado por Luciana Pinheiro. Disponível em: http://cpdoc.fgv.br/sites/default/files/verbetes/primeira-republica/LUZ,\%20Arnaldo\%20Siqueira\%20Pinto\%20da.pdf. Acesso em 18.jun.2020.
} 
se para ocupar o cargo de secretário de Agricultura no governo Antônio Carlos, presidente de Minas Gerais. A convite de Washington Luís, passou a ocupar o posto de ministro da Justiça, permanecendo até a sua deposição. Após a Revolução de 1930, foi para o exílio na Europa ${ }^{3}$. Sua trajetória indica o forte vínculo com as elites civis e militares oficialistas em Minas Gerais, inclusive com a boa relação com as lideranças que vieram a se tornar dissidentes, como Antônio Carlos.

A pasta da agricultura foi ocupada por Geminiano de Lira Castro, vice-governador do Pará entre 1901 e 1904. Fortemente vinculado às oligarquias políticas locais, foi eleito deputado federal por diversas legislaturas (DHBB CPDOC $\mathrm{FGV}^{4}$ ).

O Ministério da Fazenda, uma das mais importantes pastas, foi ocupado por Getúlio Vargas. Getúlio Vargas era descendente de uma família dominante na região de fronteira com a Argentina. Seu pai, o general Manuel Nascimento Vargas, era dirigente do Partido Republicano Riograndense em São Borja desde a Revolução Federalista. Seguindo os passos do pai, Vargas começou a carreira militar, porém abandonou esse projeto para dedicar-se à política estudantil, e destacou-se em um discurso proferido ao recém-presidente eleito, Afonso Pena, em uma visita ao Rio Grande do Sul, no ano de 1906. A oratória do jovem oligarca impressionou a Borges de Medeiros na ocasião (LOVE, 1983, p.64). Após a sua formatura em Direito, Vargas iniciou sua carreira como Promotor Público em Porto Alegre. Eleito deputado estadual, exerceu mandatos entre 1909 e 1924, tornando-se líder do governo no legislativo estadual. Entre 1924 e 1926, exerceu o mandato de deputado federal, exercendo a posição de líder da delegação gaúcha na Câmara dos Deputados (LOVE, 1983, p.64). Enquanto ministro, Vargas colocou em prática alguns princípios que faziam parte do seu pensamento, tais como o antiliberalismo, intervencionismo estatal e da necessidade de um impulso industrial (FONSECA, 2004).

No entanto, Vargas tinha ambições políticas relacionadas ao seu estado, nas vésperas das eleições de 1928. Sua carta de demissão da pasta demonstrou respeito e lealdade em relação ao presidente Washington Luís.

O substituto de Vargas, Francisco Chaves de Oliveira Botelho, era filho do diplomata Joaquim Antônio de Oliveira Botelho, com fortes vínculos oligárquicos. Começou a sua carreira política como vereador em Resende, Rio de Janeiro, sendo eleito deputado estadual em 1901. Em 1904, foi eleito deputado federal, ocupando o posto por diversas legislaturas. Foi presidente do Rio de Janeiro por

\footnotetext{
${ }^{3}$ DHBB CPDOC FGV. Verbete Augusto Viana do Castelo. Assinado por Ioneide Piffano Brion de Souza. Disponível em: $\quad$ http://cpdoc.fgv.br/sites/default/files/verbetes/primeira-republica/CASTELO,\%20Augusto\%20Viana\%20do.pdf. Acesso em 18.jun.2020.

${ }^{4}$ DHBB CPDOC FGV. Verbete Geminiano de Lira Castro. Assinado por Adrianna Setemy. Disponível em: http://cpdoc.fgv.br/sites/default/files/verbetes/primeira-republica/CASTRO,\%20Geminiano.pdf. Acesso em 18.jun.2020.
} 
duas ocasiões. Nomeado ministro da Fazenda, Washington Luís atendeu a uma antiga reivindicação que os políticos situacionistas fluminenses faziam para o governo federal (DHBB CPDOC FGV ${ }^{5}$ ).

O Ministro da Guerra, Nestor Sezefredo dos Passos, nasceu em Santa Catarina. Iniciou sua carreira militar no Rio Grande do Sul, atuando também em São Paulo, Mato Grosso e Rio de Janeiro. Combateu os movimentos tenentistas antes de ocupar o cargo de ministro. Permaneceu no mesmo até a deposição do governo Washington Luís, partindo para o exílio em Portugal. Como ministro da Guerra, recusou o fornecimento de armas a João Pessoa, na ocasião em que se deflagrou a a luta armada em Princesa, no dia 9 de junho de 1930. O presidente da Paraíba havia sido candidato à vicepresidente na chapa de Getúlio Vargas, oposicionista ao situacionismo de Washington Luís. Após o assassinato de João Pessoa, os ânimos se exaltaram e culminaram no movimento revolucionário de outubro de 1930 (DHBB CPDOC FGV ${ }^{6}$ ).

Otávio Mangabeira é proveniente de uma antiga oligarquia baiana. Seu irmão. João Mangabeira, foi deputado federal pela Bahia em diversas legislaturas, sendo posteriormente ministro das Minas e Energia em 1962, e da Justiça, de 1962 a 1963, ambos cargos ocupados durante o governo de João Goulart. Bacharel em Engenharia, Otávio Mangabeira começou sua careira política como vereador, em 1906. Obteve, desde então, grande reconhecimento como chefe político no Partido Republicano da Bahia. De 1912 a 1926, ocupou o cargo de deputado federal. Nomeado ministro das Relações Exteriores no governo Washington Luís, seu nome representou o prestígio da oligarquia baiana na política nacional (DHBB CPDOC FGV7).

O ministro da Viação e Obras Públicas, Vítor Konder, era filho do alemão Marcos Konder, que se estabeleceu em Itajaí no século XIX, formando uma família de notáveis nomes na política catarinense. Entre seus irmãos, destacam-se: Arno Konder (Cônsul-Geral do Brasil em Washington), Adolfo Konder (Governador de Santa Catarina e Deputado Federal) e Marcos Konder (Prefeito de Itajaí e deputado estadual por diversas legislaturas). Suas irmãs fizeram casamentos no interior da oligarquia política catarinense, como é o exemplo de Marieta Konder Bornhausen, casada com Irineu Bornhausen, governador de Santa Catarina. Formado em Direito, antes de ser nomeado ministro da

\footnotetext{
${ }^{5}$ DHBB CPDOC FGV. Verbete Francisco Chaves de Oliveira Botelho. Assinado por Raimundo Helio Lopes. Disponível em: http://cpdoc.fgv.br/sites/default/files/verbetes/primeira-republica/BOTELHO,\%20Oliveira.pdf. Acesso em 18.jun.2020.

${ }^{6}$ DHBB CPDOC FGV. Verbete Nestor Sezefredo dos Passos. Assinado por Robert Pechman. Disponível em: http://www.fgv.br/cpdoc/acervo/dicionarios/verbete-biografico/nestor-sezefredo-dos-passos. Acesso em 18.jun.2020.

7 DHBB CPDOC FGV. Verbete Otávio Mangabeira. Assinado por Sílvia Pantoja. Disponível em: http://www.fgv.br/cpdoc/acervo/dicionarios/verbete-biografico/mangabeira-otavio. Acesso em 18.jun.2020.
} 
Viação no governo Washington Luís, Vítor Konder desempenhou o cargo de vereador em Itajaí, deputado estadual e deputado federal (MEMÓRIA POLÍTICA ${ }^{8}$ ).

Em síntese, a composição ministerial do governo Washington Luís demonstra a alta vinculação com as oligarquias estaduais, a diversificação de estados para as pastas, agregando diferentes interesses em uma união de forças nacionais.

No entanto, a segunda metade da década de 1920 registrou o fortalecimento das oligarquias dissidentes, surgindo organizações partidárias que reivindicavam a moralização e as reformas políticas. O legado do movimento tenentista também possuía grande popularidade. No final do mandato, Washington Luís necessitava eleger o seu sucessor. Neste contexto, ocorreu a eleição presidencial de 1930, disputada pelo candidato da situação, Júlio Prestes, pelo Partido Republicano Paulista, e o candidato da oposição, Getúlio Vargas, pela Aliança Liberal. O primeiro era apoiado pelo presidente Washington Luís, que também pertencia ao Partido Republicano Paulista. As oligarquias dissidentes e grande parte dos tenentes apoiaram a oposição. A plataforma da campanha presidencial da Aliança Liberal, redigida por Lindolfo Collor (2002) apresenta críticas ao sistema político brasileiro vigente, caracterizado pela manipulação e fraudes nas eleições, pelo caciquismo, pela falta de liberdade de opinião, entre outros vícios. O candidato situacionista, Júlio Prestes, ganhou as eleições em março de 1930. Inconformados com o resultado, no dia três de outubro de 1930, militares revoltosos chefiados por Góes Monteiro, marcharam do Rio Grande do Sul com direção ao Rio de Janeiro para depor Washington Luís, com o apoio de Getúlio Vargas e do patriarca político gaúcho Borges de Medeiros (SKIDMORE, 2010). A insurreição obteve êxito, e no início de novembro de 1930, Getúlio Vargas toma posse como presidente do governo provisório.

A próxima seção analisará a primeira composição ministerial do governo provisório chefiado por Getúlio Vargas. Trata-se de uma investigação que objetiva analisar os atributos sociais e políticos dos agentes com poder e prestígio no contexto da Revolução de 1930.

\section{ANÁLISE DA PRIMEIRA COMPOSIÇÃO MINISTERIAL DO GOVERNO VARGAS}

Esta seção possui o objetivo de analisar os atributos sociais dos agentes detentores de poder ministerial no período pós-revolucionário, tendo como objetos a primeira composição do governo provisório. Nesse primeiro momento, observa-se uma notável diferença em relação ao governo

\footnotetext{
8 MEMÓRIA POLÍTICA. Vitor Konder. Disponível em: http://memoriapolitica.alesc.sc.gov.br/biografia/895-
} Vitor Konder. Acesso em 18.jun.2020. 
Washington Luís, pois a primeira composição ministerial foi substituída, em poucos meses, por novos integrantes, o que demostra a alta rotatividade de poder após a Revolução de 1930, ao contrário da estabilidade política registrada no governo Washington Luís. O quadro a seguir apresenta informações sobre a primeira composição ministerial do Governo Provisório, com os agentes empossados em novembro de 1930.

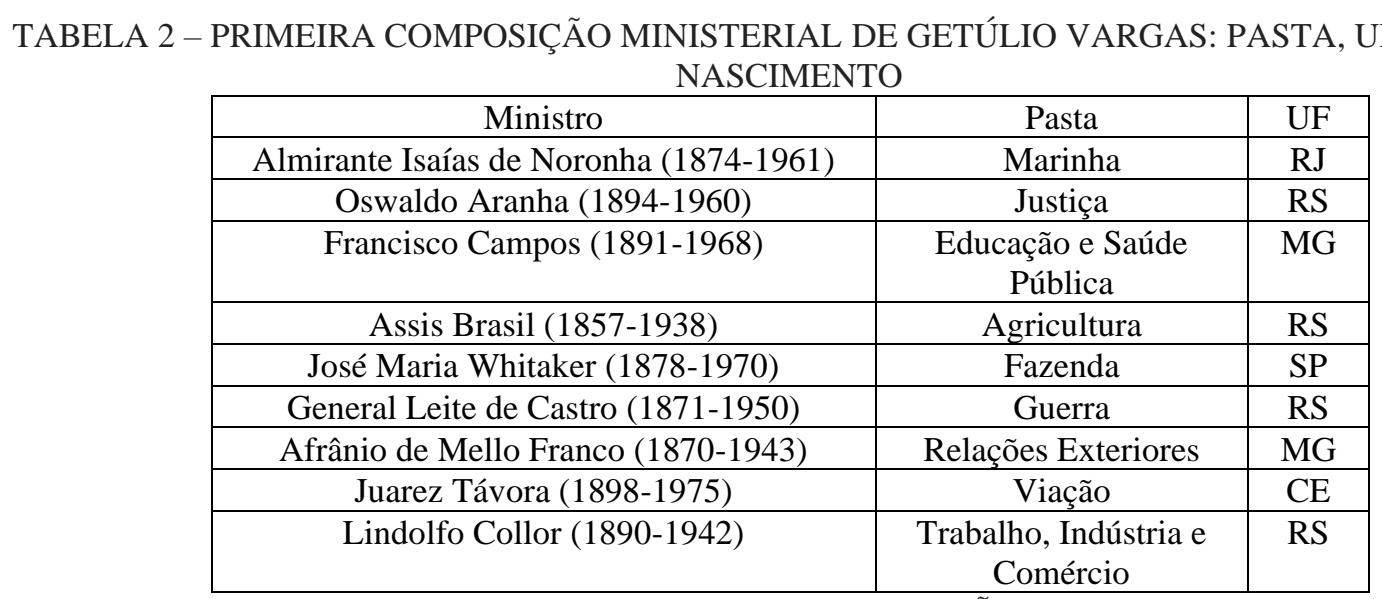

FONTE: DHBB/CPDOC/FGV. ORGANIZAÇÃO: A autora (2020)

A primeira equipe de ministros nomeada pelo Governo Provisório demonstra uma composição que procurou agregar os estados cujas oligarquias dissidentes apoiaram a Revolução, não esquecendo de incluir a representação do Nordeste e de São Paulo.

Rio Grande do Sul e Minas Gerais, estados em que as oligarquias uniram-se para apoiar a composição da Aliança Liberal contra a hegemonia paulista, e ofereceram suporte à Revolução de 1930, foram os maiores beneficiados com cargos ministeriais. O Rio Grande do Sul foi o estado que mais ascendeu nos níveis econômicos, políticos e militares no processo da Revolução de 1930. Na primeira composição ministerial, passou a ocupar quatro ministérios: da Justiça, da Agricultura, da Guerra e do Trabalho. Por sua vez, Minas Gerais ganhou duas pastas: da Educação e Saúde Pública e das Relações Exteriores.

Trata-se de um ministério majoritariamente conservador, que aglutinou membros das oligarquias políticas dissidentes nos estados. Não houve ênfase na nomeação de elementos propriamente tenentistas na equipe ministerial, somente oligarcas dissidentes próximos aos movimentos revolucionários, como é o caso de Oswaldo Aranha e Assis Brasil, no Rio Grande do Sul. Apenas um membro do tenentismo histórico, Juarez Távora, fez parte do ministério, porém, não permaneceu na pasta, passando a ocupar a delegacia militar do Norte e do Nordeste, atuando junto às 
interventorias federais, em espacial as tenentistas. Nascido na cidade cearense de Jaguaribemirim, no ano de 1898, era filho de proprietários da fazenda Embargo. Um dos seus tios maternos, Belisário Távora, foi chefe de polícia no Distrito Federal (Rio de Janeiro) no governo do marechal Hermes da Fonseca, entre os anos de 1910-1914 (DHBB CPDOC FGV9).

Uma importante característica da análise ministerial do Governo Provisório é a reforma administrativa verificada nas pastas. Os 7 ministérios existentes anteriormente (Marinha, Justiça, Agricultura, Fazenda, Guerra, Relações Exteriores e Viação e Obras Públicas) passaram a incluir duas pastas novas: o Ministério da Educação e o Ministério do Trabalho. Trata-se de importantes inclusões que evidenciam o caráter social e reformista do novo regime.

O Ministério do Trabalho, Indústria e Comércio, considerado como "Ministério da Revolução", representou um dos maiores avanços para que a questão social fosse efetivamente levada à sério como uma política de Estado.

O primeiro titular da pasta, Lindolfo Collor, era assessorado pelos socialistas Joaquim Pimenta, Evaristo de Moraes e Agripino Nazareth (BANDEIRA, 2010, p.96). Lindolfo Leopoldo Boeckel Collor foi um dos principais ideólogos do movimento de 1930, sendo o responsável pela redação da Plataforma da Aliança Liberal, divulgada em 20 de abril de 1930 (COLLOR, 2002). Nascido em São Leopoldo, no Rio Grande do Sul, no ano de 1890, suas origens sociais vinculam-se aos primeiros imigrantes alemães que aportaram no Brasil. A inserção da família junto aos luteranos possibilitou a sua formação superior em Farmácia, realizada com grandes dificuldades financeiras. Iniciando sua carreira como jornalista, logo encontrou espaço no circuito intelectual do Rio de Janeiro. Regressando ao Rio Grande do Sul, a convite de Borges de Medeiros tornou-se redator do jornal “A Federação", órgão do Partido Republicano Riograndense. Aos 31 anos, tornou-se deputado estadual, juntamente com outras jovens lideranças, como João Neves da Fontoura e Getúlio Vargas. $\mathrm{Na}$ legislatura seguinte, foi eleito deputado federal, cargo ao qual foi reeleito. Participou ativamente da Aliança Liberal e da Revolução de 1930 (DHBB CPDOC FGV ${ }^{10}$ ). Na composição ministerial, Lindolfo Collor foi uma indicação de Borges de Medeiros (LEVINE, 2001).

A tradição positivista registrada nos governos de Borges de Medeiros e Júlio de Castilhos, no que diz respeito ao amparo aos trabalhadores, ao invés da repressão, registrou-se como o começo da política de proteção ao trabalho que viria a ser desenvolvida pelo regime varguista. O programa do

\footnotetext{
${ }^{9}$ DHBB CPDOC FGV. Verbete Juarez Távora. Disponível em: http://www.fgv.br/cpdoc/acervo/dicionarios/verbetebiografico/juarez-do-nascimento-fernandes-tavora. Acesso em 17.mar.2020.

${ }^{10}$ DHBB CPDOC FGV. Verbete Lindolfo Collor. Disponível em: https://www.fgv.br/cpdoc/acervo/dicionarios/verbetebiografico/lindolfo-leopoldo-boekel-collor. Acesso em 17.mar.2020.
} 
Partido Republicano Riograndense incluía a limitação da jornada de trabalho, proteção às mulheres e menores, além de direitos relacionados às férias, aposentadorias, greves e tribunais de arbitragem para solução de conflitos entre patrões e operários (MELLO, 1984). Essa tradição foi decisiva para as ações do Ministério do Trabalho, empreendidas por Lindolfo Collor.

A estrutura institucional criada pelo Ministério do Trabalho tinha como composição o Departamento Nacional do Trabalho, o Departamento Nacional da Indústria, o Departamento Nacional do Comércio, o Departamento de Propriedade Industrial e o Instituto de Tecnologia. Outras inovações referem-se à carteira profissional e as comissões mistas de conciliação e julgamento (MUNIZ, 1978). Os direitos trabalhistas instituídos nos primeiros anos da revolução referem-se à extensão da estabilidade no emprego, das pensões e aposentadorias aos empregados em serviços público, à limitação da jornada de trabalho a oito horas no comércio e na indústria, à regulamentação das condições de trabalho das mulheres e dos menores, às convenções coletivas de trabalho, entre outros direitos previstos pelo Ministério pelas gestões subsequentes (BANDEIRA, 2010).

O Ministério da Educação e da Saúde Pública teve como seu primeiro ocupante o oligarca dissidente Francisco Luís da Silva Campos. Nascido na cidade mineira de Dores do Indaiá, em 1891, era filho de magistrado Jacinto Álvares da Silva Campos e descendente do bandeirante Antônio Rodrigues Velho, um dos fundadores da cidade mineira de Pitangui, no século XVIII. Segundo o verbete biográfico de Francisco Campos no Dicionário Histórico-Biográfico Brasileiro, muitas lideranças da Revolução de 1930 em Minas Gerais faziam parte do mesmo tronco familiar, sendo eles, além de Francisco Campos, Benedito Valadares, Gustavo Capanema, os Melo Franco, José de Magalhães Pinto, Olegário Maciel e Ovídio de Abreu. Matinho Álvares da Silva Campos, tio-avô de Francisco Campos e de Benedito Valadares, foi ministro, deputado e presidente da província do Rio de Janeiro durante o Império (DHBB CPDOC FGV ${ }^{11}$ ).

A nomeação de Francisco Campos fazia parte das exigências da oligarquia mineira dissidente que apoiou a Aliança Liberal e a Revolução de 1930 e dos setores conservadores da Igreja Católica, sob a liderança de Alceu Amoroso Lima. No entanto, no decorrer de sua gestão, Francisco Campos se distanciou do Partido Republicano Mineiro, articulando posições favoráveis à Legião Revolucionária de Minas Gerais.

Previamente à sua nomeação ao ministério, Francisco Campos havia sido deputado federal entre 1921 e 1926 e pioneiro na implantação da Escola Nova no Brasil, além de ter sido um

\footnotetext{
11 DHBB CPDOC FGV. Verbete Francisco Campos. Disponível em: https://www.fgv.br/cpdoc/acervo/dicionarios/verbete-biografico/francisco-luis-da-silva-campos. Acesso em 17.mar.2020.
} 
participante ativo da Aliança Liberal em Minas Gerais e das articulações pela Revolução de 1930 (CPDOC FGV ${ }^{12}$ ).

Durante a sua gestão à frente do Ministro da Educação, Francisco Campos empreendeu reformas, tais como a criação do Conselho Nacional de Educação; a organização do ensino superior e a estruturação do ensino secundário e comercial (HISTEDBR UNICAMP ${ }^{13}$ ).

Para o Ministério da Justiça, o escolhido foi Oswaldo Euclides de Souza Aranha, um dos maiores articuladores da Aliança Liberal e da Revolução de 1930. Nascido na cidade gaúcha de Alegrete no ano de 1884, filho do coronel Euclides Egídio de Sousa Aranha, proprietário da estância Alto Uruguai, localizada no município de Itaqui, no Rio Grande do Sul. A família Aranha era descendente da baronesa de Campinas, esposa do plantador pioneiro de café no estado de São Paulo. Um dos tios de Oswaldo Aranha era político em São Paulo. O pai de Oswaldo Aranha era chefe Partido Republicano Rio-Grandense em Itaqui. Pelo lado materno, Aranha era descendente de Luís de Freitas Vale, o barão de lbirocaí, chefe político em Alegrete, no Rio Grande do Sul. Manuel de Freitas Vale, um dos tios de Aranha, exerceu a prefeitura da cidade por vários mandatos. Oswaldo Aranha pertencia a uma família oligarca com atuação em São Paulo e no Rio Grande do Sul. Seus irmãos, Ciro Aranha e Luís Aranha, foram revolucionários de 1930, e exerceram cargos políticos no processo político (DHBB CPDOC FGV ${ }^{14}$ ).

Oswaldo Aranha mudou-se para o Rio de Janeiro para estudar Direito. Na ocasião, estabeleceu fortes vínculos de amizade com Virgílio de Melo Franco, Rubens Antunes Maciel e José Antônio Flores da Cunha, figuras decisivas no posterior processo político de 1930. Após a realização de uma especialização em Paris, regressou ao Rio Grande do Sul, para instalar um escritório de advocacia em Uruguaiana. Neste momento da carreira, estreitou os laços com o também recém-formado Getúlio Vargas.

Com vigorosa atuação na política gaúcha como defensor do grupo político de Borges de Medeiros, Oswaldo Aranha lutou contra as insurreições de protesto à quinta reeleição consecutiva do governador, comandando uma força civil e militar situacionista. Tornou-se prefeito de Alegrete entre 1925 e 1927, um reduto oposicionista de Borges de Medeiros. Com grande prestígio no Partido

\footnotetext{
${ }^{12}$ CPDOC FGV. Dossiê A Era Vargas. Disponível em: https://cpdoc.fgv.br/producao/dossies/AEraVargas1/anos3037/IntelectuaisEstado/MinisterioEducacao. Acesso em 17.mar.2020.

13 HISTEDBR UNICAMP. Verbete Reforma Educacional Francisco Campos, de 1931. Disponível em: http://www.histedbr.fe.unicamp.br/navegando/glossario/verb_c reforma francisco_campos_1931.htm Acesso em 17.mar.2020.

${ }^{14}$ DHBB CPDOC FGV. Verbete Osvaldo Aranha. Disponível em: https://www.fgv.br/cpdoc/acervo/dicionarios/verbetebiografico/osvaldo-euclides-de-sousa-aranha. Acesso em 17.mar.2020.
} 
Republicano Riograndense, Aranha foi eleito deputado federal e exerceu um papel fundamental na Aliança Liberal e na Revolução de 1930 (CPDOC FGV ${ }^{15}$ ).

No período pós-revolucionário, foi um dos fundadores do Clube 3 de Outubro e da Legião Revolucionária, órgãos de orientação tenentista em que Aranha era mentor. Enquanto ministro, Aranha foi decisivo para a nomeação dos interventores federais nos estados, entre oligarcas dissidentes e tenentes. O nome de João Alberto para a interventoria de São Paulo pela influência de Aranha (SILVA, 1972). Apesar de manter contato com os tenentes de maneira intensa e amistosa, Aranha também percebia a necessidade da organização dos grupos civis para que não se instaurasse um regime militar que desagregasse elementos unidos pelos ideais revolucionários. Essa preocupação foi demonstrada em uma carta para Borges de Medeiros, em março de 1931 (SILVA, 1972).

Joaquim Francisco de Assis Brasil, membro do Partido Libertador do Rio Grande do Sul, foi o escolhido para a pasta da Agricultura. Os dois partidos oligárquicos do Rio Grande do Sul apoiaram a Aliança Liberal e a Revolução de 1930, mesmo sendo rivais a nível estadual. Assis Brasil também possuía raízes oligárquicas. Nascido na cidade de São Gabriel, no Rio Grande do Sul, formou-se pela Faculdade de Direito de São Paulo, onde estudou com Júlio de Castilhos e se formou no ano de 1882. Seu grupo acadêmico teve contato com ideias republicanas, abolicionistas e positivistas, o que influenciou a prática política no interior do Partido Republicano Riograndense. Assis Brasil foi um dos fundadores desta agremiação, juntamente com Júlio de Castilhos. As conexões oligárquicas com os grupos que exerceram a hegemonia política durante a República Velha são evidentes na trajetória de Assis Brasil. Sua família é formada por estancieiros e latifundiários. Casou-se com Cecília Prates de Castilhos, irmã de Júlio de Castilhos, o que intensificou suas ligações com o líder republicano que exerceu duas vezes o cargo de governador do Rio Grande do Sul, a primeira em 1891 a segunda de 1893 a 1898. Em 1908, fundou o Partido Republicano Democrático, cujo programa inspirou a fundação do Partido Libertador, em 1928. Esta legenda fazia parte do Partido Democrático Nacional, presidido por Assis Brasil (DHBB CPDOC FGV ${ }^{16}$; GRANATO, 2019).

Em 1922, candidatou-se à presidência do Rio Grande do Sul, em oposição à Borges de Medeiros. Tornou-se uma das principais lideranças da Aliança Libertadora, que reuniu diversas oposições e dissidentes republicanos a partir de 1924. Foi neste ano também que participou da revolta tenentista de 1924, continuando suas atividades opositoras no seu exílio no Uruguai. Na volta ao

15 CPDOC FGV. Verbete Osvaldo Aranha. Disponível em: http://www.fgv.br/cpdoc/acervo/dicionarios/verbetebiografico/osvaldo-euclides-de-sousa-aranha. Acesso em 03.mai.2020.

${ }^{16}$ DICIONÁRIO HISTÓRICO-BIOGRÁFICO BRASILEIRO. CPDOC/FGV. Verbete Assis Brasil. Disponível em: http://www.fgv.br/cpdoc/acervo/dicionarios/verbete-biografico/joaquim-francisco-de-assis-brasil. $\quad$ Acesso em 30.nov.2018. Verbete assinado por Regina da Luz Moreira. 
Brasil, foi eleito deputado federal pela Aliança Libertadora do Rio Grande do Sul, em 1927. Suas principais bandeiras referem-se à defesa da anistia aos revolucionários tenentistas e à oposição ao governo Washington Luís. Assis Brasil mobilizou diálogos com os tenentes exilados Luís Carlos Prestes, Isidoro Dias Lopes e Miguel Costa para ensaiar possibilidades de luta armada contra as oligarquias (DHBB CPDOC FGV; GRANATO, 2019).

Outra nomeação que reforça o caráter conservador do ministério de Vargas foi o nome de Afrânio Melo Franco, para a pasta das Relações Exteriores. Membro da mesma oligarquia da qual fazia parte Francisco Campos, Afrânio Melo Franco nasceu na cidade mineira de Paracatu, em 1870. Pelo lado paterno, descendia de Manuel de Melo Franco, um dos principais líderes da Revolução Liberal de 1842 em Minas Gerais que exerceu o cargo de deputado-geral no Império, juntamente com Bernardo e Francisco de Melo Franco, seus irmãos. Pelo lado materno, descendia de famílias política de Paracatu, rivais dos Melo Franco no período imperial. Seu pai, Virgílio Martins de Melo Franco, foi magistrado em Minas Gerais e Goiás, exercendo os cargos de deputado provincial e geral no Império e senador entre 1892 e 1923, no período republicano (DHBB CPDOC FGV ${ }^{17}$ ).

Formado em Direito, começou sua carreira como promotor em Ouro Preto. A família Melo Franco exercia grande poder no interior do Partido Republicano Mineiro. Afrânio Melo Franco desempenhou o cargo de deputado estadual, de 1902 a 1906, deputado federal, de 1906 a 1918, de 1920 a 1923 e de 1927 a 1929 e Ministro da Viação, de 1918 a 1919. Foi um dos chefes da Aliança Liberal e da Revolução de 1930 (DHBB CPDOC FGV).

Os ânimos mais inflamados da Tribunal Revolucionário, instituição criada para investigar e punir membros do governo deposto, foram neutralizados por esta pasta. Afrânio de Melo Franco colocou a sua equipe a salvo das demissões convulsionadas pelo Tribunal (WIRTH, 1979, p.50).

Outro ministério de Vargas que representa o caráter de modernização conservadora foi o Ministério da Fazenda. A economia brasileira requeria confiança internacional. Para evidenciar a seguridade dos interesses cafeeiros e dos grandes setores da classe dominante paulista, José Maria Whitaker foi o escolhido para a pasta. Membro de uma abastada família, um dos seus irmãos, Firmino Antônio da Silva Whitaker Filho, foi ministro do Supremo Tribunal Federal entre os anos de 1927 e 1934. Comerciante de café, fundou o Banco Comercial do Estado de São Paulo em 1912. Entre 1920

\footnotetext{
17 DICIONÁRIO HISTÓRICO-BIOGRÁFICO BRASILEIRO. CPDOC/FGV. Verbete Afrânio de Melo Franco. Disponível em: https://www.fgv.br/cpdoc/acervo/dicionarios/verbete-biografico/franco-afranio-de-melo Acesso em 17.mar.2020.
} 
e 1922, foi presidente do Banco do Brasil. O banqueiro também era membro do Partido Democrático de São Paulo (DHBB CPDOC FGV ${ }^{18}$ ).

Nesse sentido, o governo provisório optou pelo conservadorismo no campo econômico, na tentativa de conciliação com as classes dominantes brasileiras e com a alta cúpula econômica.

Além de Whitaker, Vargas concedeu outros cargos ao Partido Democrático e à classe dominante paulista no campo econômico, mesmo diante do fato de que o Partido Democrático de São Paulo ter apoiado a Aliança Liberal, mas não a Revolução de 1930. Paulo Prado foi nomeado presidente do Conselho Nacional do Café e Paulo Nogueira Filho foi nomeado presidente da Comissão Central de Compras (FORJAZ, 1988, p.143).

Desse modo, o governo acalmou os ânimos internacionais, mantendo a estabilidade econômica e financeira para os investimentos no país. As maiores potências com que o Brasil tinha relações econômicas e diplomáticas mais estreitas reconheceram o novo governo, encarando-o com entusiasmo, pois as medidas de proteção ao café adotadas pelo governo Washington Luís também não eram vistas com agrado pelo mercado internacional (WIRTH, 1979, p.49).

Na área militar, José Isaías de Noronha assumiu o Ministério da Marinha. Nascido em 1873 na cidade do Rio de Janeiro, era membro de uma família militar, sendo o seu pai general do Exército. Isaías de Noronha desenvolveu carreira na Marinha e pertenceu a Junta Militar Provisória, pedindo demissão do cargo de ministro um mês depois da posse (DHBB CPDOC FGV ${ }^{19}$ ). Posteriormente, fez parte do "Gabinete Negro", juntamente com Francisco Campos, João Batista Luzardo, Oswaldo Aranha e Pedro Aurélio de Góis Monteiro.

O General Leite de Castro assumiu o ministério da Guerra. Nascido em 1871 na cidade de Cruz Alta, no Rio Grande do Sul, era membro de família militar, era fillho do marechal João Vicente Leite de Castro. Desenvolvendo carreira militar, em outubro de 1930 apoiou a Revolução de 1930, sendo designado ministro. Fez parte do "Gabinete Negro", considerado o embrião do Clube 3 de Outubro, organização destinada a pressionar Vargas pela manutenção do ideário tenentista (DHBB CPDOC $\mathrm{FGV}^{20}$ ).

\footnotetext{
18 DHBB CPDOC FGV. Verbete José Maria Whitaker. Disponível em: https://www.fgv.br/cpdoc/acervo/dicionarios/verbete-biografico/whitaker-jose-maria. Acesso em 17.mar.2020. 19 DHBB CPDOC FGV Verbete Isaías de Noronha. Disponível em: https://www.fgv.br/cpdoc/acervo/dicionarios/verbete-biografico/jose-isaias-de-noronha. Acesso em 17.mar.2020. ${ }^{20}$ DHBB CPDOC FGV. Verbete Leite de Castro. Disponível em: https://www.fgv.br/cpdoc/acervo/dicionarios/verbetebiografico/jose-fernandes-leite-de-castro. Acesso em 17.mar.2020.
} 


\section{CONSIDERAÇÕES FINAIS}

Entre os principais resultados da análise comparativa, destaca-se que o ministério de Washington Luís demonstrou agregação de forças políticas de diversas regiões do país. Trata-se de uma equipe estável politicamente. Por sua vez, a análise da primeira equipe de ministros nomeada pelo Governo Provisório demonstra uma composição que procurou agregar os estados cujas oligarquias dissidentes apoiaram a Revolução. No entanto, essa agregação de forças não demonstrou estabilidade política e gerou inúmeros descontentamentos e desgastes nos primeiros meses do governo provisório.

$\mathrm{Na}$ análise do ministério Vargas, destaca-se a força política dos estados do Rio Grande do Sul e de Minas Gerais. Outros pontos destacados referem-se ao caráter conservador de algumas nomeações empreendidas pelo presidente, bem como ao prestígio de lideranças associadas à sua pessoa. Nesse sentido, entendendo a Revolução de 1930 como um processo de modernização conservadora, assinala-se que o movimento questionou o sistema político oligárquico da Primeira República, mas não rompeu com as suas práticas, especialmente no campo econômico. Para a pasta da fazenda, o escolhido foi um banqueiro paulista vinculado às oligarquias dissidentes organizadas no Partido Democrático de São Paulo. Outros membros dessa agremiação foram contemplados por importantes cargos na área econômica do governo federal. Também ressalta-se que a maioria dos escolhidos para as pastas ministeriais eram provenientes de antigas famílias oligárquicas, que desfrutavam de prestígio em seus estados, porém, se sentiam preteridas pelo jogo político hegemônico, cada vez mais fechado, que anulava atuação da oposição ou grupos dissidentes.

Quanto ao caráter reformista da Revolução de 1930, percebe-se que ele foi materializado na reforma administrativa dos ministérios, em especial com a criação do Ministério da Educação e Saúde Pública e do Ministério do Trabalho, Indústria e Comércio. Trata-se de um novo olhar sobre a questão social e o papel do Estado como promotor de bem-estar social, aspecto que se intensificou como marca do governo Vargas no decorrer dos anos.

Também destaca-se o fato de Vargas agregar lideranças que articularam a Revolução de 1930, reunindo interesses da nova geração de oligarcas dissidentes, desejosos por mudanças políticas e institucionais, juntamente com movimentos vinculados ao "tenentismo revolucionário", composto por civis e militares, como é o caso de Oswaldo Aranha, escolhido para o Ministério da Justiça. 


\section{REFERÊNCIAS}

BANDEIRA, Moniz. O governo João Goulart: As lutas sociais no Brasil (1961-1964). São Paulo: Editora da UNESP, 2010.

CPDOC FGV. Dossiê A Era Vargas. Disponível em: https://cpdoc.fgv.br/producao/dossies/AEraVargas1/anos30-

37/IntelectuaisEstado/MinisterioEducacao. Acesso em 17.mar.2020.

DHBB CPDOC FGV. Verbete Afrânio de Melo Franco. Disponível em: https://www.fgv.br/cpdoc/acervo/dicionarios/verbete-biografico/franco-afranio-de-melo Acesso em 17.mar.2020.

DHBB CPDOC FGV. Verbete Arnaldo Siqueira Pinto da Luz. Assinado por Luciana Pinheiro. Disponível em: http://cpdoc.fgv.br/sites/default/files/verbetes/primeirarepublica/LUZ,\%20Arnaldo\%20Siqueira\%20Pinto\%20da.pdf. Acesso em 18.jun.2020.

DHBB CPDOC FGV. Verbete Assis Brasil. Disponível em: http://www.fgv.br/cpdoc/acervo/dicionarios/verbete-biografico/joaquim-francisco-de-assis-brasil. Acesso em 30.nov.2018. Verbete assinado por Regina da Luz Moreira.

DHBB CPDOC FGV. Verbete Augusto Viana do Castelo. Assinado por Ioneide Piffano Brion de Souza. Disponível em: http://cpdoc.fgv.br/sites/default/files/verbetes/primeirarepublica/CASTELO,\%20Augusto\%20Viana\%20do.pdf. Acesso em 18.jun.2020.

DHBB CPDOC FGV. Verbete Francisco Campos. Disponível em: https://www.fgv.br/cpdoc/acervo/dicionarios/verbete-biografico/francisco-luis-da-silva-campos. Acesso em 17.mar.2020.

DHBB CPDOC FGV. Verbete Francisco Chaves de Oliveira Botelho. Assinado por Raimundo Helio Lopes. Disponível em: http://cpdoc.fgv.br/sites/default/files/verbetes/primeirarepublica/BOTELHO,\%20Oliveira.pdf. Acesso em 18.jun.2020.

DHBB CPDOC FGV. Verbete Geminiano de Lira Castro. Assinado por Adrianna Setemy. Disponível em: http://cpdoc.fgv.br/sites/default/files/verbetes/primeirarepublica/CASTRO,\%20Geminiano.pdf. Acesso em 18.jun.2020.

DHBB CPDOC FGV. Verbete Isaías de Noronha. Disponível em: https://www.fgv.br/cpdoc/acervo/dicionarios/verbete-biografico/jose-isaias-de-noronha. Acesso em 17.mar.2020.

DHBB CPDOC FGV. Verbete José Maria Whitaker. Disponível em: https://www.fgv.br/cpdoc/acervo/dicionarios/verbete-biografico/whitaker-jose-maria. Acesso em 17.mar.2020.

DHBB CPDOC FGV. Verbete Juarez Távora. Disponível em: http://www.fgv.br/cpdoc/acervo/dicionarios/verbete-biografico/juarez-do-nascimento-fernandestavora. Acesso em 17.mar.2020. 
DHBB CPDOC FGV. Verbete Leite de Castro. Disponível em: https://www.fgv.br/cpdoc/acervo/dicionarios/verbete-biografico/jose-fernandes-leite-de-castro. Acesso em 17.mar.2020.

DHBB CPDOC FGV. Verbete Lindolfo Collor. Disponível em: https://www.fgv.br/cpdoc/acervo/dicionarios/verbete-biografico/lindolfo-leopoldo-boekel-collor. Acesso em 17.mar.2020.

DHBB CPDOC FGV. Verbete Nestor Sezefredo dos Passos. Assinado por Robert Pechman. Disponível em: http://www.fgv.br/cpdoc/acervo/dicionarios/verbete-biografico/nestor-sezefredodos-passos. Acesso em 18.jun.2020.

DHBB CPDOC FGV. Verbete Osvaldo Aranha. Disponível em: https://www.fgv.br/cpdoc/acervo/dicionarios/verbete-biografico/osvaldo-euclides-de-sousa-aranha. Acesso em 17.mar.2020.

DHBB CPDOC FGV. Verbete Otávio Mangabeira. Assinado por Sílvia Pantoja. Disponível em: http://www.fgv.br/cpdoc/acervo/dicionarios/verbete-biografico/mangabeira-otavio. Acesso em 18.jun.2020.

FORJAZ, Maria Cecília Spina. Tenentismo e Aliança Liberal (1927-1930). São Paulo: Livraria e Editora Polis, 1988.

GRANATO, Natália Cristina. O Partido Democrático Nacional de 1927 a 1929: um estudo dos capitais familiares e políticos dos seus dirigentes. In: $19^{\circ}$ Congresso Brasileiro de Sociologia. Em que sociedades vivemos? A Sociologia brasileira diante de novos desafios nacionais e globais contemporâneos, 2019, Florianópolis (SC). GT 31- Família, Instituições e Poder, 2019.

HISTEDBR UNICAMP. Verbete Reforma Educacional Francisco Campos de 1931. Disponível em:

http://www.histedbr.fe.unicamp.br/navegando/glossario/verb_c_reforma_francisco_campos_1931.h tm Acesso em 17.mar.2020.

LEVINE, Robert. Pai dos pobres? O Brasil e a era Vargas. São Paulo: Companhia das Letras, 2001.

LOVE, Joseph. A Revolução de 1930 e o Regionalismo Gaúcho. In: UFRGS (org.). Simpósio sobre a Revolução de 30. Porto Alegre: Erus, 1983.

MARTINS, Luciano. A Revolução de 1930 em Perspectiva: Estado, Estrutura de Poder e Processo Político. In: A revolução de 30: Seminário realizado pelo Centro de Pesquisa e Documentação de História Contemporânea do Brasil (CPDOC) da Fundação Getúlio Vargas. Brasília: Editora Universidade de Brasília, 1983.

MELlO, José Octávio de Arruda. A Revolução estatizada: Um estudo sobre a formação do centralismo em 30. João Pessoa: Fundação Guimarães Duque, 1984.

MEMÓRIA POLÍTICA. Vitor Konder. Disponível em: http://memoriapolitica.alesc.sc.gov.br/biografia/895-Vitor_Konder. Acesso em 18.jun.2020.

MUNIZ, Heitor. Depoimento ao CPDOC. Rio de Janeiro: Fundação Getúlio Vargas, 1978. 
PIRES, Murilo José de Souza; RAMOS, Pedro. O termo modernização conservadora: sua origem e utilização no Brasil. Revista Econômica do Nordeste. Fortaleza, vol.40, $\mathrm{n}^{\circ} 3$, julho-setembro de 2009, pp.411-424.

SILVA, Hélio. 1931: Os tenentes no poder (O ciclo de Vargas- volume IV). Rio de Janeiro: Civilização Brasileira, 1972.

SKIDMORE, Thomas. Brasil: de Getúlio a Castello (1930-64). São Paulo: Companhia das Letras, 2010.COLLOR, Lindolpho. Manifesto da Aliança Liberal, redigido por Lindolfo Collor (20 abril 1930). In: BONAVIDES, Paulo; AMARAL, Roberto (orgs.). Textos Políticos da História do Brasil (Volume 4). Brasília: Senado Federal, 2002.

SOUZA, Maria do Carmo Campello de. Estado e Partidos Políticos no Brasil (1930 a 1964). São Paulo: Alfa-Ômega, 1976.

STONE, Lawrence. Prosopografia. Revista de Sociologia e Política, Curitiba, vol.19, n.39, 2011

WIRTH, John D. O Tenentismo na Revolução de 30. In: FIGUEIREDO, Eurico de Lima (org.). Os militares e a Revolução de 1930. Rio de Janeiro: Paz e Terra, 1979.

WIRTH, John D. O Tenentismo na Revolução de 30. In: FIGUEIREDO, Eurico de Lima (org.). Os militares e a Revolução de 1930. Rio de Janeiro: Paz e Terra, 1979. 